\title{
PERCEPÇÕES E DEMANDAS DE NUTRICIONISTAS DA ALIMENTAÇÃO ESCOLAR SOBRE SUA FORMAÇÃO
}

\author{
PERCEPTIONS AND DEMANDS OF SCHOOL MEAL NUTRITIONISTS ABOUT THEIR TRAINING
}

PERCEPCIONES Y DEMANDAS DE NUTRICIONISTAS DE LA ALIMENTACIÓN ESCOLAR

SOBRE SU FORMACIÓN

Andréa Riskala Franco Honório ${ }^{1}$

Sylvia Helena Batista ${ }^{2}$

Resumo A pesquisa teve por objetivo conhecer as percepções e demandas dos nutricionistas atuantes na alimentação escolar sobre sua formação nessa área da nutrição. A investigação foi realizada por meio de aplicação de questionário autopreenchível a 39 participantes de uma capacitação para nutricionistas que atuam no Programa Nacional de Alimentação Escolar em 2008. Os dados foram analisados mediante a utilização de abordagem qualitativa. A maioria considerou que a graduação não preparou adequadamente para a atuação na área, já que temas pertinentes ao Programa Nacional de Alimentação Escolar não são, ou são pouco abordados. Apesar das dificuldades e queixas, a maioria manifestou satisfação com sua prática na alimentação escolar, porém pressupõe ser necessária alguma mudança, tendo demonstrado desconforto com a própria prática. Este estudo reforça a importância de ampla discussão sobre a formação do nutricionista e a adequação dos currículos às demandas atuais.

Palavras-chave nutricionista; alimentação escolar; formação profissional; educação em saúde.
Abstract The study aimed to understand the perceptions and demands imposed on nutritionists active in the preparation of meals served at schools on their training in this area of nutrition. The research was conducted through a self-administered questionnaire replied to by 39 participants in a training session held for nutritionists who worked under the National School Nutrition Program in 2008. Data were analyzed by means of a qualitative approach. Most professionals considered that their training had not prepared them adequately to act in the area, as issues relevant to the National School Nutrition Program were either not addressed at all or poorly discussed. Despite their difficulties and complaints, most said they were satisfied with their practice in school meals, but believed changes are needed and were not comfortable with the practice itself. This study underpins the importance of holding a broad discussion on the nutritionists' training and on the curricula's adequacy to address current demands.

Keywords nutritionist, school meals; vocational training; health education. 


\section{O nutricionista e a alimentação escolar}

Embora registros das primeiras iniciativas em Alimentação Escolar (AE) tenham acontecido na década de 1940 no Rio de Janeiro e em São Paulo, foi na de 1950 que se estruturou pela primeira vez um programa de merenda escolar em âmbito nacional sob responsabilidade pública (Fundo Nacional de Desenvolvimento da Educação, [2009]). Em 1954, Josué de Castro, na primeira edição da Cartilha da merenda escolar (Brasil, 1956), incluiu um plano de trabalho denominado Programa Nacional de Merenda Escolar para elevar os níveis de nutrição e combater a fome, racionalizando e estendendo ao país os programas de merenda escolar já existentes. Em 31 de março de 1955, o decreto n. 37.106 instituiu a Campanha de Merenda Escolar, subordinada ao Ministério da Educação. Em 1960 eram atendidos mais de dois milhões de escolares, em 1.661 municípios (Stefanini e Szarfarc, 1997).

O programa, atualmente denominado Programa Nacional de Alimentação Escolar (PNAE), de caráter suplementar, tem uma função estratégica na consolidação do direito humano à alimentação adequada, pois, além de atender às necessidades nutricionais, visa à formação de hábito alimentar saudável durante a permanência dos alunos na escola, contribuindo para seu crescimento, desenvolvimento, aprendizagem e rendimento escolar (Batista et al., 2007). O PNAE é gerido pelo Fundo Nacional de Desenvolvimento da Educação (FNDE) e beneficiou em 2012 cerca de 43 milhões de alunos da educação básica em todo o país, com orçamento previsto em $\mathrm{R} \$ 3,5$ bilhões para 2013 (Fundo Nacional de Desenvolvimento da Educação, [2007]).

A presença do nutricionista na AE é determinada e regulamentada pelo Conselho Federal de Nutricionistas (CFN), por meio da resolução CFN n. 465/2010, que dispõe sobre as atribuições do profissional no âmbito do Programa de Alimentação Escolar (PAE). Ele assume a responsabilidade técnica, compromisso profissional e legal na execução das atividades, de acordo com a formação e os princípios éticos da profissão, visando à qualidade dos serviços prestados à sociedade. A ele compete, no exercício de suas atribuições, planejar, organizar, dirigir, supervisionar, avaliar os serviços de alimentação e nutrição, prestar assistência e realizar educação nutricional à comunidade escolar, entre outras atividades (Conselho Federal de Nutricionistas, 2010). O nutricionista tem na AE a oportunidade de assumir outros papéis além de administrador de refeições, seu potencial como educador em nutrição, para atuar na transformação do espaço da merenda escolar em um ambiente de promoção da saúde e de aprendizagem, pois a alimentação saudável se inclui nos requisitos de promoção da saúde no ambiente escolar, definidos pela Organização Pan-Americana da Saúde/Organização Mundial da Saúde (Opas/OMS) (Azevedo et al., 1999). 
De acordo com o FNDE, em maio de 2009 estavam cadastrados nessa autarquia 4.559 nutricionistas atuando na $\mathrm{AE}$ em todo o Brasil. No primeiro trimestre de 2005 estavam cadastrados apenas 1.300, e é possível afirmar que essa área de atuação encontra-se em franco crescimento. Entre 2005 e 2009, o número de nutricionistas atuando na AE cresceu 350\%.

Apesar de vários autores traçarem o histórico da AE no Brasil, pouco se fala do percurso do nutricionista no desenvolvimento desse campo de atuação. $\mathrm{O}$ nutricionista ganha força como categoria profissional à medida que seu campo de atuação se amplia. Pode-se dizer que, na década de 1970, a recente regulamentação da profissão, a criação do Instituto Nacional de Alimentação e Nutrição (Inan), a realização do Programa Nacional de Alimentação e Nutrição (Pronan) I e II, as especificações crescentes da AE e a criação dos cursos de nutrição no setor privado foram as responsáveis pelo fortalecimento do campo de atuação do nutricionista. Além disso, surgiram avanços no sentido da organização como categoria com a criação do CFN, em 1978 (a fiscalização até então cabia ao Conselho de Medicina), e dos conselhos regionais, em 1980. Pode-se observar que, até meados dos anos 1980, a categoria atuava em AE com um número singelo de profissionais. A partir das descentralizações, em 1994, o nutricionista começou a ser solicitado e a ingressar nessa área de forma mais intensa (Calil e Aguiar, 1999).

Entre 1985 e 2000, ocorreu crescente processo de mobilização e politização dos nutricionistas. A lei n. 8.234, de 17 de setembro de 1991 (revogou a lei n. 5.276/67), estabeleceu não somente o campo de atuação do nutricionista como também suas atividades privativas e instrumentos legais para sua identificação, reforçando o papel dos conselhos como órgãos fiscalizadores do exercício legal da profissão (Conselho Federal de Nutricionistas, 2010).

Outro fator que pode ter incentivado e fortalecido a presença do profissional na AE foi a escolha de uma nutricionista, Albaneide Peixinho, para a coordenação geral do PNAE, no FNDE. Houve uma mudança na concepção assistencialista do programa com a redefinição de diretrizes que passaram a contemplar a AE como um direito das crianças, garantido pelas políticas de Segurança Alimentar e Nutricional (SAN) e pela Constituição Federal. A AE passou a ter um comprometimento com a melhora da aprendizagem e do rendimento escolar e com a formação de hábitos alimentares saudáveis.

\section{O nutricionista e sua formação}

O nutricionista surgiu no Brasil nos anos 30 e 40 do século passado como dietista, atuando no ambiente hospitalar com a responsabilidade de prestar assistência ao paciente quanto à alimentação e à administração no controle 
de custos e gastos. Tratava-se de um profissional de nível médio, cuja formação e campo de prática eram predefinidos pelos ideólogos da problemática alimentar brasileira da época, os médicos nutrólogos (Santos, 1988). Aos poucos, os cursos foram sofrendo alterações, aproximando-se das características do curso do Instituto Nacional de Nutrição da Argentina, sob a influência do médico Pedro Escudero. Formavam um profissional de nível universitário com conhecimentos específicos de nutrição, com funções e responsabilidades próprias de atenção dietética ao indivíduo sadio ou enfermo, de forma individual ou coletiva (Icaza, 1991).

O processo de formação do nutricionista brasileiro, idealizado pela primeira geração de médicos nutrólogos, iniciou-se na década de 1940, quando foram criados os quatro primeiros cursos do país, em São Paulo e Rio de Janeiro (Vasconcelos, 2002). Observa-se que o termo 'nutricionista' aparece usado na criação do primeiro curso para formação de nutricionistas do Instituto de Higiene da Universidade de São Paulo, em 1939, e vai se consolidando à medida que outros cursos surgem.

A graduação do nutricionista manteve-se restrita a apenas sete cursos até a década de 1970, quando ocorreu explosivo aumento do ensino superior no país, a partir da Reforma Universitária, que incrementou a formação profissional em todos os cursos da área da saúde. Em 1982, já eram registrados trinta cursos para graduação do nutricionista no Brasil (Gil, 1986). Nas décadas de 1980 e 1990 ocorreu intensa ampliação de cursos, pelas conquistas dos nutricionistas como categoria profissional e com aumento expressivo de profissionais no mercado de trabalho. Na década de 1980, foram criados 12 cursos e, em 1996, o CFN já registrava um total de 45 cursos de graduação. Esse número continuou aumentando expressivamente nos anos seguintes, chegando a 123 em 2000, 383 em 2009 e 420 em 2013 (Conselho Federal de Nutricionistas, 2013). Essa característica de crescimento expressivo vem mantendo-se atualmente e reflete também o aumento no número de profissionais com registro definitivo no CFN, principalmente entre os anos de 2000 e 2009, quando esse número subiu de 24.731 para 44.974 profissionais registrados (Conselho Federal de Nutricionistas, 2009). O CFN registrava 76.445 profissionais até o segundo trimestre de 2013.

O exercício profissional pressupõe um corpo de conhecimento e habilidades, estabelecendo uma estreita relação entre 'saber' e 'profissão'. O controle sobre determinada esfera do conhecimento apresenta-se, portanto, como uma questão crucial para os profissionais em busca de construção de uma identidade e um aspecto fundamental à profissionalização (Bosi, 1996).

A formação e a atuação do nutricionista têm sido estudadas e discutidas. Entretanto, há carência de estudos e análises que apontem situações a serem corrigidas e aspectos a serem aprofundados no processo de formação, visando à sua prática profissional (Prado e Abreu, 1991; Paraná, 2004). 
Embora também pareça necessário promover alterações nos currículos da graduação, privilegiando aspectos político-sociais em momentos reflexivos, dialógicos e de pesquisa, não se trata apenas disso. É preciso compreender que há uma formação profissional importante que ocorre após a graduação, na medida em que vão acontecendo experiências na prática de trabalho.

Entre os estudos conhecidos, é consenso a presença de conteúdos excessivamente teóricos nos currículos, direcionados aos aspectos biológicos da graduação, e o distanciamento entre a formação acadêmica e a prática profissional (Brasil, 1983; Ypiranga, 1991; Bosi, 1988, 1996).

Segundo Imbernón (2004), as tendências mais atuais no campo da educação apontam para a necessidade de voltar o ensino para a realidade da vida profissional futura, empregando uma metodologia presidida pela pesquisa-ação como importante estratégia de aprendizagem, a fim de propiciar a reflexão necessária para construir e reconstruir a teoria a partir da prática, aprendendo a lidar com o inesperado. Emerge daí a necessidade de se pensar na continuidade do processo de formação desse profissional (pós-graduação), visando aprimorar sua prática cotidiana e melhorar a dinâmica do trabalho.

No sentido de contribuir para ampliar a formação profissional do nutricionista, especialmente o que atua na AE, a Educação Permanente aparece como necessária e pontual na atualização cotidiana das práticas e na construção coletiva do perfil profissional. Pensando nela como ferramenta fundamental nesse processo de formação, é possível dizer que ela articula saberes e práticas, suprindo as questões eventualmente não contempladas pelo foco teórico da graduação (Juzwiak, Castro e Batista, 2013).

A Educação Permanente é um processo de ensino e aprendizagem dinâmico e contínuo, tendo como finalidade análise e aprimoramento da capacitação de pessoas e grupos para enfrentarem a evolução tecnológica, as necessidades sociais e atenderem aos objetivos e metas da instituição a que pertencem.

Tem como objeto de transformação o processo de trabalho, orientado para a melhoria da qualidade dos serviços, partindo da reflexão sobre o que está acontecendo no serviço e sobre o que precisa ser transformado (Girade, Cruz e Stefanelli, 2006).

De acordo com Ceccim (2005), para produzir mudanças nas práticas de gestão e atenção, é fundamental dialogar com as práticas e concepções vigentes, problematizá-las e construir novos pactos de convivência e práticas.

Partindo dessas constatações, faz-se necessário captar as percepções do profissional sobre suas práticas e as demandas de formação do grupo. A pesquisa teve como objetivo a criação de uma proposta de formação para os nutricionistas atuantes na $\mathrm{AE}$, com base nas afirmações dos próprios profissionais sobre sua prática de trabalho. 


\section{Aspectos metodológicos}

O universo do estudo 3 foi composto por uma amostra intencional de 39 nutricionistas que estavam participando da Capacitação para Nutricionistas do PNAE, evento realizado pelo Centro Colaborador em Alimentação e Nutrição Escolar da Universidade Federal de São Paulo (Cecane/Unifesp), nas cidades de Jundiaí, Taubaté e Sorocaba, no período de outubro a novembro de 2008. O Cecane é uma unidade de referência e apoio constituída entre o FNDE e as instituições federais de ensino superior (Ifes) para desenvolver ações e projetos no âmbito do PNAE. Entre suas competências está planejar, organizar e executar projetos de capacitação dos diversos atores envolvidos com o PNAE, dentre eles o nutricionista (Brasil, 2013).

Dada a natureza do estudo, optou-se por usar uma abordagem qualitativa, modalidade que permite verificar o significado atribuído pelos sujeitos à realidade de suas práticas. As pesquisas que utilizam essa abordagem trabalham com valores, crenças, representações, hábitos, atitudes e opiniões, visando entender o contexto em que algum fenômeno ocorre (Landim et al., 2006).

A pesquisa descritiva foi realizada por meio da aplicação de um questionário estruturado autopreenchível, considerando-se que estaria reunido um grupo representativo da categoria que se desejava estudar - todos juntos e ao mesmo tempo sendo trabalhados intensamente conteúdos que poderiam influenciar as respostas. Assim, seria prudente que a coleta das informações ocorresse antes de iniciar as atividades, para não atrapalhar o andamento da capacitação, tampouco influenciar os dados coletados.

O questionário, composto por vinte questões organizadas em quatro eixos temáticos, foi um instrumento com perguntas abertas, mistas e fechadas. Testou-se a adequação do instrumento por meio de um estudo-piloto. Coletaram-se os termos de consentimento livre e esclarecido de todos os nutricionistas envolvidos na pesquisa, bem como dos participantes no estudo-piloto.

Os dados obtidos pelos questionários foram tratados de duas formas. Os que traziam o perfil profissional foram analisados de forma descritiva, com abordagem quantitativa. Já as necessidades e demandas de formação, que traziam as questões abertas, foram analisadas usando abordagem qualitativa.

Para analisar as questões abertas definiu-se por utilizar a análise de conteúdo, cujo foco é a mensagem expressa pelo sujeito, em que o analista busca categorizar as unidades de texto (palavras ou frases) que se repetem, inferindo uma expressão que as represente, procurando compreender o pensamento do sujeito pelo conteúdo expresso no texto (Caregnato e Mutti, 2006). Algumas questões foram tratadas pelo método de 'dedução frequencial', que consiste em enumerar a ocorrência de uma mesma palavra ou tema que se repete com frequência nas respostas, apresentando descrições numéricas, enquanto com outras questões foi usada a 'análise por categorias 
temáticas', que constrói as categorias conforme emergem do texto para encontrar uma série de significações (Caregnato e Mutti, 2006). Escolhemos nomear de unidade temática cada objetivo específico proposto pela pesquisa, o que gerou, então, seis unidades temáticas: caracterização dos sujeitos, motivação para atuar no PNAE, percepções sobre sua formação para atuar na área, atividades técnicas mais importantes, dificuldades no cotidiano do PNAE e satisfação com a prática profissional.

O projeto foi submetido ao Comitê de Ética em Pesquisa da Universidade Federal de São Paulo (CEP/Unifesp) e aprovado em 25/07/2008.

\section{Dos achados e suas lições: a(o) nutricionista da alimentação escolar em foco}

Todas as 39 nutricionistas entrevistadas são mulheres, dado que corrobora outras pesquisas com nutricionistas, em que o gênero é predominantemente feminino, variando de $96 \%$ a $98 \%$ do universo (Akutsu, 2008; CFN, 2006; Andrade e Lima, 2003; Sadcovitz, 1997; Bosi, 1996). Apesar de o tempo de formação acadêmica variar muito, $51 \%$ da amostra têm até dez anos de graduação, número pouco abaixo do encontrado pela pesquisa nacional CFN, que aponta que $70 \%$ dos nutricionistas têm até dez anos de formação (Conselho Federal de Nutricionistas, 2006).

No que se refere ao tempo, observou-se que $61 \%$ das nutricionistas trabalhavam há menos de cinco anos na AE. Desse percentual, quase 30\% atuavam na área há apenas um ano. Apenas 15\% tinham mais de dez anos, o que pode sugerir que os nutricionistas com mais tempo de formação não costumam permanecer. É preciso considerar que o aumento da demanda pelo profissional nessa área ocorreu há poucos anos, após a descentralização do PNAE em 1994, o que pode contribuir para explicar esse dado.

Para conhecer a motivação para atuar na $\mathrm{AE}$, o objetivo era saber se os nutricionistas escolheram por ela ou aproveitaram uma oportunidade de trabalho que surgira. A questão orientadora ancorava-se na existência ou não de afinidade ou interesse pela área que os levou à opção. Os dados mostram que $59 \%$ dos profissionais ingressaram nela para aproveitar uma oportunidade de trabalho e não porque a almejavam ou tinham planejado. Entre estes, $38 \%$ disseram ter sido aprovados em concurso público, o que sugere a estabilidade como fator preponderante na escolha do emprego. É frequente o relato de que prestaram concurso para uma vaga no campo da saúde e depois tiveram que assumir a AE do município ou foram redirecionados para lá.

Importante destacar que Zimmermann (2007) afirma que quem escolhe a área de atuação por afinidade, aproximação, interesse, identificação, o faz consciente do que quer, tendo mais condições de exercer suas atividades 
com mais motivação e dedicação. Busca sua adequação profissional correspondente às suas aptidões e interesses. Uma boa escolha profissional reflete boas perspectivas ocupacionais, trabalhadores qualificados e comprometidos com suas atividades profissionais.

Quanto à percepção sobre a formação para atuar na área, 79\% observaram que a graduação não as preparou adequadamente, alegando que não são ou são pouco abordados assuntos pertinentes à $\mathrm{AE}$, como 'legislação do PNAE', 'administração de recursos públicos', 'licitação', 'prestação de contas', 'descrição de produtos para editais', 'controle de qualidade' e 'atribuições do nutricionista'. Os sujeitos sinalizaram a tendência da graduação em privilegiar outras áreas da Nutrição, como Nutrição Clínica e Alimentação Coletiva (focando a alimentação do trabalhador). A falta de estágios na área, estágios não adequados ou insuficientes também aparecem pontuados como uma falha da graduação.

Esses dados foram confirmados na pesquisa de Costa (1996) com egressos da Universidade Federal de Goiás, segundo a qual o principal ponto frágil da graduação está relacionado à carga horária insuficiente para a prática e à dissociação entre teoria e prática, ponto também abordado em estudo de Saar e Trevizan (2007). Em estudos de Rodrigues (2004) e Amorim, Moreira e Carraro (2001), os estágios curriculares também são apontados como falhos. A carga horária prática dedicada à atuação na comunidade é restrita, e os estágios curriculares geralmente acontecem no último ano, senão no último semestre do curso, após o acadêmico ter concluído todos os demais créditos ou disciplinas, dificultando a retroalimentação e novos direcionamentos dos conteúdos trabalhados.

Embora pareça comum o fato de que o recém-formado, em qualquer área de formação, ache que a graduação não foi suficiente para prepará-lo para atuar no mercado de trabalho, predomina nos discursos desta pesquisa uma opinião coesa e objetiva de que as atribuições dos nutricionistas da $\mathrm{AE}$ são pouco ou nada exploradas na graduação, inclusive nos estágios curriculares - e assim continuam, a despeito do crescimento da demanda por profissionais nessa área de atuação. Tal opinião aparece mesmo entre as nutricionistas que se formaram recentemente. Paradoxalmente, a AE tem se mostrado uma das áreas de atuação para os nutricionistas que mais crescem no Brasil atualmente.

Ao investigar as atividades técnicas que os nutricionistas elegeram mais importantes no desenvolvimento de suas atribuições, foi possível notar nas respostas muita afinidade entre as atividades eleitas primordiais e as previstas pela resolução CFN n. 358/2005, que dispunha, na época da pesquisa, sobre as competências do nutricionista no exercício de suas atividades no âmbito do PAE (Conselho Federal de Nutricionistas, 2010). As atividades técnicas eleitas mais importantes, pela ordem, foram: desenvolver projetos 
de educação nutricional com a comunidade escolar (pais, alunos, professores e coordenadores); capacitar agentes do PAE (cozinheiras e ajudantes); elaborar os cardápios a partir das especificidades da população atendida; e supervisionar as unidades educacionais (incluindo visitas técnicas).

A atividade eleita como a mais importante pelas nutricionistas desta pesquisa foi a 'Educação Nutricional', citada em $64 \%$ das respostas. A Educação Nutricional constitui importante estratégia de ação em saúde pública. É disciplina obrigatória nos cursos de Nutrição e faz parte das ações do nutricionista em todos os campos de atividade, segundo a lei federal n. 8.234/91, que regulamenta a profissão. Pode e deve ser utilizada como importante instrumento de apoio na promoção da saúde, aproveitando o espaço criado pelo PAE para analisar e discutir esses fatores e refletir sobre eles (Costa, Ribeiro e Ribeiro, 2001). Ao analisar, entre docentes, métodos qualitativos e quantitativos na área da Saúde, Turato (2005) confirma que o nutricionista é visto como educador em todas as áreas de atuação. Para os docentes, tal significado é compartilhado, podendo ser chamado de significado coletivo.

Uma das prováveis explicações para a grande preocupação que o nutricionista tem em aplicar a Educação Nutricional no seu cotidiano de trabalho é a necessidade de levar para sua prática questões que o identifiquem mais com a área da saúde (Bosi, 1996). Viana (1996) aborda a questão da identidade profissional conflituosa do nutricionista e afirma que é possível compreender por que a Educação Nutricional aparece em primeiro lugar na hierarquia do modelo ideal de prática. Na percepção do grupo, tal seria a principal via para se reconhecer e se fazer reconhecer como profissional de saúde.

Em relação à capacitação das cozinheiras, as nutricionistas participantes desta pesquisa parecem bastante conscientes da necessidade de aprimoramento constante desses profissionais, que têm contato direto e diário com a alimentação e com as crianças. Ao analisar dados de prefeituras que concorriam ao Prêmio Gestor Eficiente da Merenda Escolar - planejado pela organização não governamental Ação Fome Zero em 2004 e 2005 -, Belik e Chaim (2006) perceberam que a capacitação de merendeiras é a prática mais comum, já que em $92,4 \%$ (em 2004) e 76,3\% (em 2005) dos casos essa prática é realizada com frequência semestral ou anual nas prefeituras que concorriam ao prêmio.

Também a elaboração dos cardápios, a supervisão e a fiscalização das unidades educacionais aparecem bastante citadas nas respostas, provavelmente porque os nutricionistas reconhecem sua importância para garantir a qualidade da AE desde o processo de compra e entrega do produto até a operacionalização técnica de pré-preparo e preparo das refeições (Andrade et al., 2004). A supervisão garante o cumprimento dos cardápios, o preparo correto da merenda e a manutenção da segurança higiênica e sanitária das refeições produzidas (Tenuta, 2008). Ao conhecer a realidade do grupo em 
que atua, o nutricionista deve adequar os recursos disponíveis, garantindo o respeito às disposições legais, para equacionar problemas identificados na comunidade à qual presta assistência dietética (Domene, 2008).

Quando perguntada sobre as 'maiores dificuldades para cumprir suas tarefas cotidianas', a grande maioria das participantes enumerou várias dificuldades, agrupadas pelas pesquisadoras em duas categorias:

1) 'Dificuldades relativas às atribuições do nutricionista' (como lidar com as cozinheiras e ajudantes e como gerenciá-las, balancear cardápios, fazer avaliação e Educação Nutricional). Entre as mais citadas estão 'gerenciamento das merendeiras', 'desmotivação da equipe', 'capacitação de agentes', 'desenvolvimento de projetos de Educação Nutricional (faltam tempo e informações técnicas)', 'dificuldade técnica para lidar com teste de aceitabilidade e licitação', 'balanceamento do cardápio com a verba disponível' e 'adequação às diferentes faixas etárias atendidas pelo programa'.

A dificuldade prevalente foi a complexa 'relação com as cozinheiras (merendeiras) e sua gestão', o fato de a maioria ser concursada e não ter seu cargo ameaçado refletindo no baixo comprometimento no desempenho de suas tarefas. Também foram citados o pouco preparo técnico para o desempenho das tarefas, a falta de comprometimento e o baixo nível de escolaridade das cozinheiras, o que torna ainda mais difícil o relacionamento. O desafio do nutricionista, no contato diário com as cozinheiras, tem sido administrar os conflitos no sentido de melhorar suas condições de trabalho, estabelecer bons vínculos com essas profissionais, criar e executar capacitações constantes e exclusivas a cada ambiente de trabalho e manter boa rede de colaboração entre elas e com elas na prática cotidiana. De fato, essa gestão exige do profissional uma série de qualificações necessárias à gestão de pessoas que provavelmente não estão entre os conteúdos abordados na graduação, sequer encontrados em livros ou congressos.

2) 'Dificuldades relativas à administração local do programa' (como falta de profissionais para atender à demanda, escassez de investimentos na área, pouca integração com as secretarias de Educação e de Saúde). Esta última categoria, diretamente relacionada à gestão local do programa, concentrou a maior parte das respostas (apareceu em $84 \%$ dos questionários). Entre as dificuldades mais citadas estão 'baixa valorização do nutricionista', 'pessoas leigas na chefia e em todo o processo interferindo nas questões da alimentação', 'falta de nutricionistas para atender à demanda', 'verba reduzida para as despesas', 'compra de produtos de baixa qualidade e atraso nas entregas (falhas na licitação)', 'falta de apoio e comunicação com secretarias da Saúde e Educação', 'infraestrutura inadequada das cozinhas das UEs' e 'interesses políticos dispostos à frente dos interesses do programa'.

Há uma queixa constante, presente nos questionários enumerados em ordem de data de coleta, sobre a baixa valorização do trabalho do nutri- 
cionista que atua nessa área. É perceptível nos depoimentos que essa baixa valorização profissional parece passar à margem do nutricionista, sendo atribuída sempre aos outros envolvidos na $\mathrm{AE}$, como professores, diretores, secretários de educação e prefeitos:

A valorização do trabalho desenvolvido por nós, nutricionistas. Muitas tarefas que tentamos desenvolver no dia a dia são consideradas inúteis, 'frescura' de nutricionista (Q21).

A falta de reconhecimento do nutricionista e da importância da alimentação saudável dada pelos governantes. A cumplicidade e o compromisso das merendeiras com o serviço (Q29).

O baixo reconhecimento social e a desvalorização profissional são preocupações antigas da categoria e abrangem diversas áreas de atuação do nutricionista (Bosi, 1996; Garcia, 2006, apud Soares, 2007).

Bosi (2000), ao estudar o cotidiano de trabalho de nutricionistas sociais, já trazia e aprofundava uma discussão sobre as cargas e os sofrimentos presentes na subjetividade do grupo. Os resultados indicavam a presença de importantes cargas, com o predomínio das mentais e psicoafetivas sobre as físicas, destacando-se o medo, a ansiedade, o sentimento de desânimo e a impotência - cargas relacionadas, por um lado, à problemática sobre a qual atuam e, por outro, à formação profissional da categoria, percebida como insuficiente para uma atuação mais eficaz.

Ao olhar mais atentamente para os resultados obtidos, é interessante notar que justamente as atividades que as nutricionistas julgam mais importantes no seu trabalho também aparecem listadas entre as maiores dificuldades no cumprimento das tarefas: 'desenvolver projetos de educação nutricional', 'capacitar cozinheiras' e 'balancear cardápios considerando peculiaridades'. Provavelmente, tal resultado possa ser explicado pelo grau de complexidade dessas tarefas, uma vez que elas demandam mais tempo, saberes técnicos específicos, busca por informações atualizadas e interação com outros profissionais. É possível perceber que, apesar de as nutricionistas identificarem que suas maiores dificuldades estão ligadas à administração local do programa (isto é, elas dependem da ação de outros profissionais e setores), também se mostram conscientes da própria dificuldade em cumprir suas atribuições, limitadas, muitas vezes, pela grande quantidade de tarefas ou escassez de profissionais na AE do município para compartilhar tarefas. Ressalta-se que elas manifestam enfraquecimento pela baixa valorização de seu trabalho, o que pode contribuir para aumentar suas dificuldades.

Para conhecer a opinião das nutricionistas sobre sua 'satisfação com a prática profissional', foi utilizada como norteadora uma questão que 
abordava o desejo de mudar de área de atuação. L'Abbate (1999), Bardagi, Lassance e Paradiso (2003) e Rodrigues (2004) também empregaram essa mesma relação para conhecer a satisfação profissional entre os participantes de suas pesquisas.

Apesar de citar várias dificuldades para exercer sua prática profissional, a maioria das nutricionistas pesquisadas (59\% da amostra) afirma que 'não' pensa em mudar de área de atuação. Pode-se inferir, então, que a maioria das nutricionistas da amostra manifesta 'satisfação' com sua prática cotidiana na AE:

Porque gosto muito do que faço, apesar das dificuldades; é gratificante o trabalho e existe resultado e retorno; você acompanha as crianças desde a creche, apesar do salário baixo pela responsabilidade que temos (Q33).

Porque eu adoro o que faço! (Q9).

Neste estudo, a satisfação com a prática profissional no PNAE emerge ancorada na declaração das participantes de gostarem e terem afinidade com o que fazem, identificarem-se com esse trabalho, gostarem do dinamismo e dos grandes desafios assumidos, da conquista vagarosa de seus espaços e da satisfação com os resultados.

É interessante notar que isso não se repete em pesquisas com nutricionistas que atuam em outra área da Nutrição. Boog, Rodrigues e Silva (1989) e Rodrigues (2004), em seus estudos com nutricionistas atuantes em outra área da Alimentação Coletiva, apontam como prevalente a insatisfação profissional, ligada, sobretudo, ao acúmulo de atividades rotineiras, insuficiência de pessoal auxiliar, longa jornada de trabalho. Ao pesquisar a satisfação de egressos do curso de Nutrição da Universidade Federal de Ouro Preto, Rodrigues (2004) percebeu que os profissionais que atuavam na Nutrição Clínica e Docência foram os que mais manifestaram satisfação, enquanto os que atuavam na Alimentação Coletiva foram os que mais manifestaram vontade de mudar de área.

Entretanto, 11 das nutricionistas participantes desta pesquisa disseram estar em dúvida quanto à mudança de área, alegando, entre outros motivos, a baixa remuneração e o desejo de atuar em outra área: a Nutrição Clínica. Queixaram-se de que o salário é baixo, a remuneração não as valoriza e algumas parecem estar desmotivadas, o que aparece em algumas respostas e até na forma como várias preencheram o questionário, com respostas curtas e sem reflexão. As que afirmaram pensar em mudar de área de atuação apenas $13 \%$ da amostra - citam como razões a busca por melhor remuneração e valorização profissional, desestímulo e desgaste psicológico e o desejo de atuar em outra área: 
Pelo desgaste psicológico que tenho, em virtude do sistema político que oprime e exige posições que são desfavoráveis e antiéticas ao profissional (Q4).

Estou há muito tempo na área e gostaria de ter novas experiências para crescer mais profissionalmente e, se possível, com uma remuneração melhor. Falta nesta área feedback dos clientes (Q3).

Quando se compara a 'satisfação profissional' com o 'tempo de atuação na área', observa-se que as nutricionistas mais insatisfeitas e que pensam em mudar de área são as que têm, em média, maior tempo de atuação na AE: 11 anos.

Outra dimensão comparada à 'satisfação profissional' foi a 'motivação para atuar no PNAE': tornou-se evidente a diferença entre as nutricionistas que foram trabalhar na área porque a escolheram e as que aproveitaram uma oportunidade de emprego. Entre as 23 profissionais que estão satisfeitas com seu trabalho, 56\% foram atuar nessa área porque queriam, gostavam ou tinham interesse/afinidade. No entanto, entre as cinco que afirmaram o desejo de mudar de área manifestando insatisfação, apenas uma $(20 \%)$ foi trabalhar na AE porque escolheu. As outras quatro indicaram ter aproveitado uma oportunidade. Embora tais números não se mostrem suficientes para inferências, podem sinalizar que esse tema deve ser retomado em outras pesquisas.

É possível afirmar que, neste estudo, as nutricionistas que foram trabalhar na área de AE por afinidade, interesse, gosto ou escolha sentiam-se mais satisfeitas com seu trabalho. Entretanto, os dados sugerem que, quando a profissional apenas aproveita uma oportunidade de emprego, sem manifestar afinidade ou interesse pela área, há maior chance de ficar insatisfeita no trabalho e querer mudar o campo de atuação.

Ainda que manifestem satisfação com a prática cotidiana, $87 \%$ das nutricionistas desta pesquisa opinaram que é necessária alguma mudança para melhorar sua rotina de trabalho, demonstrando estarem conscientes de que há desconforto com a própria prática e que, apesar de todos os problemas, têm um desejo de mudança.

\section{Considerações finais}

A pesquisa aqui tratada teve o intuito de contribuir para a reflexão e a discussão sobre a formação de um nutricionista cada vez mais preparado para as questões que se apresentam no âmbito da sua atuação na área de AE. Os dados obtidos nos permitem perceber algumas características sobre o profissional que atua especificamente nessa área. Os nutricionistas acreditam 
que a graduação 'não' os preparou adequadamente para a atuação na $\mathrm{AE}$, uma vez que os currículos abordam pouco as questões específicas da área, como licitação, prestação de contas, legislação do PNAE, entre outras.

Predomina nos discursos uma opinião coesa e objetiva de que as atribuições dos nutricionistas atuantes nessa área são pouco ou nada exploradas pela graduação, inclusive nos estágios curriculares, a despeito do crescimento da demanda por profissionais nesse campo. Esse parece ser um paradigma que perdura há tempos, já que aparece nos discursos tanto dos nutricionistas recém-formados quanto dos formados há mais tempo.

A atividade técnica relatada pelos participantes como a mais importante desempenhada pelo nutricionista que atua na AE foi a 'Educação Nutricional', que, embora seja uma importante estratégia em saúde pública, pode estar ligada à necessidade de identificação do profissional com a área da saúde, uma vez que ele desempenha muitas atividades ditas 'administrativas' no cotidiano da AE. A Educação Nutricional pode também representar o desejo do nutricionista de intervir numa realidade inadequada da alimentação infantil, promovendo a segurança alimentar e nutricional no ambiente escolar.

É possível perceber o conflito vivido por essas profissionais quando confrontadas com sua prática: o que elas valorizam e gostariam de realizar e o que é possível fazer com base na realidade. A Educação Nutricional, citada também como uma das dificuldades enfrentadas no desempenho de seu trabalho, pode indicar uma zona tempestuosa na prática do nutricionista da AE, um dos grandes temas que devem ser trabalhados coletivamente. Nos próximos anos, essa discussão será intensificada e deverá ser campo para vários trabalhos, pois a lei n. 11.947/2009 recomenda sua introdução no currículo escolar, abordando temas como alimentação saudável, nutrição e SAN.

Entre as dificuldades mais citadas para cumprir tarefas cotidianas estão as 'relativas à gestão local do programa', âmbito em que os nutricionistas manifestam exercer pouca ou nenhuma influência, e as 'relativas às atribuições do nutricionista no programa'. É também constante a queixa sobre a 'baixa valorização do trabalho do nutricionista' nessa área, pontuada como uma ação que 'emerge' dos outros profissionais que atuam no ambiente escolar. Essa parece ser uma preocupação antiga que acompanha o profissional e abrange diversas áreas de atuação do nutricionista. Ao se analisar a importância desses discursos, começa a surgir a necessidade de apoio e capacitação desses profissionais, já que muitas das questões relacionadas podem ser trabalhadas coletivamente em oficinas que explorem a prática.

O nutricionista parece ainda conviver com o paradigma da grande quantidade de atribuições (regulamentadas e previstas em lei) com suas complexidades versus número insuficiente de profissionais para compar- 
tilhar essas tarefas. O desafio que emerge das percepções apresentadas parece ser melhorar suas condições de trabalho nessa área de atuação.

Este estudo também reforça a importância de ampla discussão sobre a formação do nutricionista contemporâneo e a adequação dos currículos às demandas atuais dessa formação. Particularmente, em relação à área de AE, tais adequações tornam-se fundamentais e urgentes, por três grandes razões: temos uma das maiores 'políticas públicas de alimentação escolar' do mundo (campo fértil para atuação do nutricionista); a área tem uma 'legislação específica' que trata das atribuições do profissional; e ainda poderemos ter um 'crescimento expressivo na demanda de profissionais' com a lei n. 11.947/2009, que amplia suas responsabilidades e possibilidades de atuação na área de AE (Brasil, 2009).

Devemos pensar, então, em formar profissionais preparados para atender a essa demanda, reconhecendo a pertinência e a importância da Educação Permanente nessa formação. Como ferramenta na formação ou capacitação dos profissionais, a Educação Permanente traz como contribuição a organização estratégica do processo de trabalho, a melhoria das relações profissionais entre agentes escolares, o estímulo à reflexão sobre a prática e as mudanças necessárias. O desafio é estimular o desenvolvimento da consciência nos profissionais sobre o seu contexto, pela sua responsabilidade em seu processo permanente de capacitação. Deve ser um processo sistematizado e participativo, tendo como cenário o próprio espaço de trabalho, no qual o pensar e o fazer são insumos fundamentais do aprender e do trabalhar (Ricaldoni e Sena, 2006; Juzwiak, Castro e Batista, 2013).

\section{Colaboradores}

Andréa Riskala Franco Honório responsabilizou-se pela produção e análise dos dados, bem como pela elaboração do artigo. Sylvia Helena Batista orientou a pesquisa, participando em parceria e coautoria na elaboração do artigo. 
Resumen La investigación tuvo como objetivo conocer las percepciones y demandas de los nutricionistas que actúan en la alimentación escolar sobre su formación en esta área de la nutrición. La investigación se realizó a través de un cuestionario autorrellenable a 39 participantes de una capacitación para nutricionistas que participan en el Programa Nacional de Alimentación Escolar, en 2008. Los datos se analizaron utilizando el enfoque cualitativo. La mayoría consideró que la graduación no los preparó adecuadamente para actuar en el área, ya que cuestiones pertinentes al Programa Nacional de Alimentación Escolar no son tratados o lo son muy poco. A pesar de las dificultades y quejas, la mayoría expresó su satisfacción con su práctica en la alimentación escolar, sin embargo, presuponen que son necesarios algunos cambios, y mostraron inquietud con su propia práctica. Este estudio refuerza la importancia de una amplia discusión sobre la formación del nutricionista y la adecuación de los planes de estudio a las demandas actuales.

Palabras clave nutricionista; alimentación escolar; formación profesional; educación en salud.

\section{Notas}

1 Universidade Federal de São Paulo, Centro de Desenvolvimento do Ensino Superior em Saúde, São Paulo, SP, Brasil.

Especialista em Nutrição Materno-Infantil para médicos e nutricionistas pela Universidade Federal de São Paulo.

$<$ andrea.riskala@terra.com.br>

Correspondência: Rua Dr. Sergio Fleury, 107, CEP 05305-060, São Paulo, SP, Brasil.

2 Universidade Federal de São Paulo, Departamento de Saúde, Educação e Sociedade, São Paulo, SP, Brasil.

Doutora em Psicologia da Educação pela Pontifícia Universidade Católica de São Paulo.

<sylvia.batista@unifesp.br>

3 Este artigo é resultado da dissertação de mestrado Nutricionistas da Alimentação Escolar que atuam no interior de São Paulo: percepções e demandas sobre sua formação para atuar nesta área, de autoria de Andrea Riskala Franco Honorio, apresentada para obtenção do titulo de Mestre Profissional em Ensino em Ciências da Saúde ao Centro de Desenvolvimento do Ensino Superior em Saúde, da Universidade Federal de São Paulo. 


\section{Referências}

AKUTSU, Rita de C. Os nutricionistas brasileiros: perfil profissional e demográfico. Revista de Nutrição, Campinas, v. 21, n. 1, p. 7-19, jan./fev. 2008.

AMORIM, Suely T. S. P.; MOREIRA, Herivelto; CARRARO, Telma E. Formação de pediatras e nutricionistas: a dimensão humana. Revista de Nutrição, Campinas, v. 14, n. 2, p. 111-118, maio/ago. 2001.

ANDRADE, Flavia F. et al. Merenda escolar: municipalização e atribuições do nutricionista. Revista Higiene Alimentar, Instituto Ponto Crítico de Ensino, São Paulo, v. 18, n. 124 , p. 43-49, set. 2004.

ANDRADE, Lucia P.; LIMA, Eronildes S. A formação e a prática do nutricionista: o gênero nas entrelinhas. Nutrire: Revista da Sociedade Brasileira de Alimentação e Nutrição, São Paulo, v. 26, p. 109-126, dez. 2003. Disponível em: <www.revistanutrire.org.br/ articles/view/id/4f982e781eflfacd37000004>. Acesso em: nov. 2013.

AZEVEDO, Ana Maria F. et al. Saúde e Nutrição em escolares. Saúde em Foco, Rio de Janeiro, v. 3, n. 18, p. 27-32, 1999. (Informe Epidemiológico em Saúde Coletiva da Secretaria Municipal de Saúde do Rio de Janeiro).

BARDAGI, Marucia P.; LASSANCE, Maria Celia P.; PARADISO, Angela C. Trajetória acadêmica e satisfação com a escolha profissional de universitários em meio de curso. Revista Brasileira de Orientação Profissional, São Paulo, v. 4, n. 1-2, p. 153-166, dez. 2003.

BATISTA, Sylvia H. et al. Manual de capacitação para nutricionistas do PNAE. São Paulo: Centro Colaborador em Alimentação e Nutrição Escolar, Universidade Federal de São Paulo (Cecane/Unifesp), 2007.

BELIK, Walter; CHAIM, Nuria A. A gestão do Programa Nacional de Alimentação Escolar e o desenvolvimento local (apresentação sem presença de debatedor). Campinas: Unicamp,
2006. Disponível em: <www.sober.org.br/ palestra/5/240.pdf>. Acesso em: 20 nov. 2009.

BOOG, Maria Cristina F.; RODRIGUES, Karla R. M.; SILVA, Sônia M. F. da. Situação profissional dos nutricionistas egressos da Puccamp. II. Relações hierárquicas, atuação profissional, avaliação da formação recebida, percepção de si como profissional da saúde, atualização e filiação a entidades profissionais. Revista de Nutrição (Puccamp), v. 2, n. 1, p. 55-87, 1989.

BOSI, Maria Lucia M. A face oculta da nutrição: ciência e ideologia. Rio de Janeiro: Espaço e Tempo/UFRJ, 1988.

BOSI, Maria Lucia M. Profissionalização e conhecimento: a nutrição em questão. São Paulo: Hucitec, 1996.

BOSI, Maria Lucia M. Trabalho e subjetividade: cargas e sofrimento na prática da Nutrição Social. Revista de Nutrição, Campinas, v. 13, n. 2, p. 107-115, maio/ago. 2000.

BRASIL. Ministério da Educação e Cultura. Campanha da Merenda Escolar. Cartilha de merenda escolar. 1. caderno. 2. ed. Rio de Janeiro, 1956. BRASIL. Ministério da Educação. Secretaria de Ensino Superior. Os cursos de nutrição no Brasil: evolução, corpo docente e currículo. Brasília: Ministério da Educação, 1983. 280 p. (Série Cadernos das Ciências da Saúde, n. 6).

BRASIL. Lei n. 11.947/2009. Dispõe sobre o atendimento da Alimentação Escolar e do Programa Dinheiro Direto na Escola aos alunos da Educação Básica. Diário Oficial da União, 16 de junho de 2009, p. 2. Disponível em: <www.planalto.gov.br/ccivil_ 03/_Ato2007-2010/2009/Lei/L1 1947.htm>. Acesso em: nov. 2013.

BRASIL. Ministério da Educação e Cultura. Fundo Nacional de Desenvolvimento para Educação. Programa Nacional de Alimentação Escolar. Manual de Operação das Parcerias 
entre o FNDE e as IFES, no Âmbito do PNAE. Brasília: MEC, 2013. Disponível em: $<$ www.fnde.gov.br/programas/alimentacao -escolar/centros-colaboradores-e-uae>. Acesso em: jan. 2015.

CALIL, Ricardo M.; AGUIAR, Janice. Nutrição e administração nos serviços de alimentação escolar. São Paulo: Markovitch, 1999.

CAREGNATO, Rita C. A.; MUTTI, Regina. Pesquisa qualitativa: análise de discurso versus análise de conteúdo. Texto \& Contexto Enfermagem, Florianópolis, v. 15, n. 4, p. 679-684, out./dez. 2006.

CECCIM, Ricardo B. Educação Permanente em Saúde: desafio ambicioso e necessário. Interface: Comunicação, Saúde, Educação, Botucatu, v. 9, n. 16, p. 161-177, set. 2004/fev. 2005. Disponível em: <www.escoladesaude.pr.gov. br/arquivos/File/textos \%20eps/educacao permanente.pdf $>$. Acesso em: nov. 2013.

CONSELHO FEDERAL DE NUTRICIONISTAS (CFN). Perfil da atuação profissional do nutricionista no Brasil (ficha catalográfica). Brasília: CFN, 2006. Disponível em: <www. cfn.org.br/novosite/pdf/pesquisa.pdf $>$. Acesso em: nov. 2013.

CONSELHO FEDERAL DE NUTRICIONISTAS (CFN). Quadro estatístico do $2^{\circ}$ trimestre de 2009. Disponível em: <www.cfn.org. br/novosite/arquivos/ESTATISTICO-2TRIMESTRE-2009-x.pdf>. Acesso em: nov. 2013.

CONSELHO FEDERAL DE NUTRICIONISTAS (CFN). Resolução CFN n. 465, de 28 de agosto de 2010. Dispõe sobre as atribuições do nutricionista no âmbito do Programa de Alimentação Escolar (PAE) e dá outras providências. Disponível em: <www.fnde. gov. br/fndelegis/action/UrlPublicasAction.php? acao $=$ abrirAtoPublico\&sgl_tipo $=$ RES\&num_ ato $=00000465 \&$ seq_ato $=000 \& v l r \_a n o=2010 \&$ sgl_orgao=CFN/EFEPL > . Acesso em: nov. 2013.

CONSELHO FEDERAL DE NUTRICIONISTAS (CFN). Quadro estatístico do $2^{\circ}$ trimestre de 2013. Disponível em: <www.cfn.org.br/ eficiente/sites/cfn/pt-br/site.php?secao= estatisticas>. Acesso: nov. 2013.

COSTA, Ester Q.; RIBEIRO, Vitoria M. B.; RIBEIRO, Eliana C. O. Programa de Alimentação Escolar: espaço de aprendizagem e produção de conhecimento. Revista de Nutrição, Campinas, v. 14, n. 3, p. 225-229, set./dez. 2001.

COSTA, Nilce Maria S. C. Repensando a formação acadêmica e a atuação profissional do nutricionista: um estudo com os egressos da Universidade Federal de Goiás (UFG). Revista de Nutrição, Campinas, v. 9, n. 2, p. 154-177, jul./dez. 1996.

DOMENE, Semiramis M. A. A escola como ambiente de promoção da saúde e educação nutricional. Revista Psicologia USP, São Paulo, v. 19, n. 4, p. 505-517, dez. 2008.

FUNDO NACIONAL DE DESENVOLVIMENTO DA EDUCAÇÃO (FNDE). Histórico da Alimentação Escolar. [2009]. Disponível em: $<$ www.fnde.gov.br/programas/alimentacaoescolar/alimentacao-escolar-historico $>$. Acesso em: nov. 2013.

FUNDO NACIONAL DE DESENVOLVIMENTO DA EDUCAÇÃO (FNDE). Dados estatísticos da Alimentação Escolar. [2009]. Disponível em: $<$ www.fnde.gov.br/programas/alimentacaoescolar/alimentacao-escolar-apresentacao $>$. Acesso em: nov. 2013.

GIL, Maria de Fátima. Recursos humanos em Nutrição no Brasil: nutricionistas. Cadernos de Saúde Pública, Rio de Janeiro, v. 2, n. 4, p. 561-569, out./dez. 1986.

GIRADE, Maria da Graça; CRUZ, Emirene MARIA N. T.; STEFANELLI, Maguida C. Educação continuada em Enfermagem Psiquiátrica: reflexão sobre conceitos. Revista da Escola de Enfermagem da USP, São Paulo, v. 40, n. 1, p. 105-110, 2006. Disponível em: $<$ www.scielo.br/scielo.php?script $=$ sci arttext\&pid $=$ S0080-62342006000100015 $>$. Acesso em: nov. 2013.

ICAZA, Suzana J. Evolución histórica de la formación del nutricionista-dietista en América 
Latina. In: REUNIÓN DE COMISIÓN DE ESTUDIOS SOBRE PROGRAMAS ACADÉMICOS EN NUTRICIÓN Y DIETÉTICA DE AMÉRICA LATINA, 4. Puerto Rico: Opas, 1991. p. 51-62.

IMBERNÓN, Francisco. Formação docente e profissional: formar-se para a mudança e a incerteza. 4. ed. São Paulo: Cortez, 2004.

JUZWIAK, Claudia R.; CASTRO, Paula M. de; BATISTA, Sylvia H. S. da S. A experiência da Oficina Permanente de Educação Alimentar e em Saúde (Opeas): formação de profissionais para a promoção da alimentação saudável nas escolas. Ciência \& Saúde Coletiva, Rio de Janeiro, v. 18, n. 4, 2013.

L'ABBATE, Solange. Educação e serviços de saúde: avaliando a capacitação dos profissionais. Cadernos de Saúde Pública, Rio de Janeiro, v. 15, supl. 2, 1999.

LANDIM, Fatima L. P. et al. Uma reflexão sobre as abordagens em pesquisa com ênfase na integração qualitativo-quantitativa. Revista Brasileira em Promoção da Saúde (RBPS) - Unifor, Fortaleza, v. 19, n. 1, p. 53-58, 2006. Disponível em: <www.unifor.br/index. php?option $=$ com_content $\&$ view $=$ article $\&$ $\mathrm{id}=560 \&$ Itemid=386> . Acesso em: nov. 2013.

PARANÁ, Simone F. P. A formação do nutricionista: sob o olhar da relação teoria e prática. Dissertação (Mestrado em Educação) - Pontifícia Universidade Católica, Curitiba, 2004.

PRADO, Shirley D.; ABREU, Miriam S. D. Nutricionista: onde trabalha? Quais suas condições de trabalho? Revista de Nutrição (Puccamp), Campinas, v. 4, n. 1/2, p. 65-92, jan./dez. 1991.

RICALDONI, Carlos Alberto C.; SENA, Roseni R. de. Educação Permanente: uma ferramenta para pensar e agir no trabalho de Enfermagem. Revista Latino-Americana de Enfermagem, Ribeirão Preto, SP, v. 14, n. 6, nov./dez. 2006. Disponível em: <www.scielo. br/scielo.php?pid=S010411692006000600002 $\&$ script $=$ sci_arttext\&tlng $=\mathrm{pt}>$. Acesso em: nov. 2013.
RODRIGUES, Karla M. Condições de trabalho do nutricionista egresso da Universidade Federal de Ouro Preto/MG: subsídios para a construção de indicadores qualitativos de satisfação profissional. Dissertação (Mestrado em Saúde Coletiva) - Fundação Oswaldo Cruz, Rio de Janeiro, 2004.

SAAR, Sandra Regina C.; TREVIZAN, Maria Auxiliadora. Papéis profissionais de uma equipe de saúde: visão de seus integrantes. Revista Latino-Americana de Enfermagem, Ribeirão Preto, SP, v. 15, n. 1, jan./fev. 2007. Disponível em: <www.scielo.br/pdf/rlae/v15nl/ pt_v15nlal6.pdf>. Acesso em: nov. 2013.

SADCOVITZ, Angela L. O nutricionista formado na cidade do Rio de Janeiro e o mercado de trabalho. Dissertação (Mestrado em Nutrição) - Instituto de Nutrição, Universidade do Estado do Rio de Janeiro, Rio de Janeiro, 1997.

SANTOS, Sandra Maria C. Nutricionista e sociedade brasileira: elementos para abordagem histórico-social da profissão. Dissertação (Mestrado em Saúde Comunitária) -Universidade Federal da Bahia, Salvador, 1988.

SOARES, Nadia T. Diretrizes curriculares nacionais para cursos de graduação em $\mathrm{Nu}$ trição e competências profissionais para atuação em segurança alimentar e nutricional: perspectivas dos docentes do Ceará. Tese (Doutorado em Saúde Coletiva) - Instituto de Medicina Social, Universidade do Estado do Rio de Janeiro, Rio de Janeiro, 2007.

STEFANINI, Maria Lucia R.; SZARFARC, Sophia C. Merenda escolar: história, tendências e contribuição no atendimento das necessidades nutricionais da criança. $101 \mathrm{f}$. Tese (Doutorado em Saúde Pública) - Faculdade de Saúde Pública, Universidade de São Paulo, São Paulo, 1997.

TENUTA, Beatriz. Entrevista. Controle de qualidade na produção e exposição de iguarias de serviços de buffet. Revista Nutrição em Pauta, n. 92, set./out. 2008. Disponível em: $<$ www.nutricaoempauta.com.br/lista_artigo. php?cod=775 >. Acesso em: nov. 2013. 
TURATO, Egberto R. Métodos qualitativos e quantitativos na área da Saúde: definições, diferenças e seus objetos de pesquisa. Revista de Saúde Pública, São Paulo, v. 39, n. 3, p. 507-514, 2005.

VASCONCELOS, Francisco A. G. O nutricionista no Brasil: uma análise histórica. Revista de Nutrição, Campinas, v. 15, n. 2, p. 127-138, maio/ago. 2002.

VIANA, Solange V. Nutrição, trabalho e sociedade: uma identidade profissional em conflito. São Paulo: Hucitec, 1996.
YPIRANGA, Lucia. Relatório apresentado à Asbran e aos cursos de nutrição do Brasil. [s.l.: s.n.], 1991. Informe sobre a participação brasileira na IV Reunião da Comissão de Estudos sobre Programas Acadêmicos em Nutrição e Dietética da América Latina, San Juan, Porto Rico.

ZIMMERMANN, Anita. A escolha profissional na área da Saúde: a opção pela Enfermagem. Dissertação (Mestrado em Educação) - Universidade Estadual de Campinas, Campinas, 2007.

Recebido em 28/08/2012

Aprovado em 20/11/2013 